\title{
Pharmacotherapy for Obesity and Changes in Eating Behavior: a Patient and Physician's Perspective
}

Piper L. Miguelgorry · Ed J. Hendricks

Received: April 4, 2016/ Published online: May 31, 2016

(C) The Author(s) 2016. This article is published with open access at Springerlink.com

\begin{abstract}
This article, co-authored by a patient with obesity, diabetes, and hypertension, and an obesity medicine specialist, discusses the patient's experience with the onset of diabetes complicating obesity and with her frustration living with these diagnoses until finding an obesity medicine specialist physician who helped her lose weight and reverse her diabetes. The patient continues to maintain a significant weight loss and is diabetes free for 5.5 years after treatment initiation. The physician discusses the application of combination treatment that can be effective in diabetes reversal in such cases. He also discusses salient clinical lessons exemplified by this case.
\end{abstract}

Enhanced content To view enhanced content for this article go to http://www.medengine.com/Redeem/ 14D4F0606572B3CB.

P. L. Miguelgorry

Folsom, CA, USA

E. J. Hendricks ( $\square)$

The Center for Weight Management, Roseville, CA, USA

e-mail: edhendricks@surewest.net
Keywords: Bupropion/naltrexone; Diabetes; Energy restriction; Ketogenic diet; Liraglutide; Lorcaserin; Low carbohydrate; Obesity; Phentermine; Weight loss

\section{PATIENT'S EXPERIENCE}

My story began years and years ago, knowing I had become plumper than I should be for my height, age, and short $5^{\prime} 2^{\prime \prime}$ stature. I was carrying rolls of uncomfortable weight, particularly around my midsection, eating more and larger portions than I needed, and not being discretionary with food choices. I grew up the oldest child of five and helped raise my four brothers and sisters. I assisted my mother, a single parent, with their care and, unknowingly, took on more responsibilities than is ordinary for such a young person.

I clearly remember eating my siblings' leftover food in the hope they would not be as hungry as I seemed to be most of the time. Our family often ate from a box such as Hamburger Helper $^{\circledR}$, Macaroni \& Cheese $^{\circledR}$, canned vegetables, pre-made spaghetti, or a TV dinner. We also ate food cooked in bulk with minimal, if any, nutrition and always with more 
carbohydrate than protein. Diversity of flavor was not a priority then.

During my adult life, I made multiple attempts to take off undesirable pounds with popular low-fat diet strategies such as Jennie Craig $^{\circledR}$, Weight Watchers ${ }^{\circledR}$, and NutriSystem ${ }^{\circledR}$. I recall eliminating 20 to $25 \mathrm{lb}$ each time, then slowly regained all of it and more. Physicians had told me during those years that I needed to lose weight, and that I had too large of a midsection that could lead to a heart attack. However, the physicians did not educate me that being overweight or obese could put me at risk for diabetes and other serious illnesses. Although they implied my weight was a medical problem, they neither treated me themselves nor referred me to a physician who would. Receiving no treatment I gradually gained more weight. When I was diagnosed with diabetes, hypertension, and high cholesterol in mid-life I was treated with sitagliptin, metformin, a statin, and an antihypertensive medicine but still did not receive treatment for obesity. I felt ashamed, hurt, and not in control of my own health. I was told to adopt a healthy eating style. I honestly believed I already understood how to do that, so I did not think to complain.

Then, 5 years ago, I went to a work-related picnic, and noticed a friend that had transformed her body by losing $30 \mathrm{lb}$ under the care of an obesity medicine specialist in my community. My friend looked healthier, happier, and slender. I was in awe. Seeing her made me realize I needed to become a patient of a physician willing to treat my obesity. A few weeks later, I entered into a medical practice weight management program. After an evaluation by the physician that included a review of my medical history, an electrocardiogram, a body composition analysis, and a physical examination I was a bit shocked when my new doctor told me my fat mass was $44 \%$ of my total weight of $174 \mathrm{lb}$. He prescribed a very low carbohydrate, ketogenic diet and the anti-obesity medicine phentermine. I was also started on a multivitamin, vitamin $\mathrm{D}$, and several other nutritional supplements. Over the course of 6 months, as I continued on this regimen I lost $50 \mathrm{lb}$. Surprisingly, even though I was on an energy-restricted diet, my energy level was higher than it had been in years, and I was only hungry when I ignored my eating schedule and waited too long before eating.

During the 9 months as I was losing weight, my doctor examined me weekly at first, then every 2 weeks. At each visit, he checked my weight and my blood pressure. He listened to my heart, questioned me about potential medication side effects, and then discussed what I was eating, commenting on what was good and bad in the process. Between my time with the doctor and with his nutritionist, who I also saw on some visits, I learned a great deal about my own metabolism and what foods were and were not a part of healthy eating. My past, present, and future eating and exercise behaviors were also frequent topics of conversation at my doctor's visits.

I was happy with my weight loss but after several months on their maintenance program, still on phentermine and a low carbohydrate eating style, I regained a few pounds. I had experimented with increasing my carbohydrate intake and the result was that I began to crave sugar, I ate more, and I gained weight. To my dismay I noted that I was losing control of my eating. My doctor then suggested continuing the phentermine and adding a second anti-obesity drug, lorcaserin. To my relief, after starting the second drug my cravings disappeared with return of complete control of my eating. Presently, 5.5 years after starting my 
new life, I am 50 lb lighter, five sizes smaller, and am successfully maintaining my weight loss. I continue to see my obesity medicine physician quarterly, I am still taking a combination of phentermine and lorcaserin, and have had no adverse effects. I am now retired and can enjoy all the activities my husband and I had looked forward to during our working years. I sometimes gain a few pounds when we travel but I always get back on my maintenance regimen when at home.

My diabetes is gone and I no longer take any medicines for it. I am still on an antihypertensive, but at a lower dose, and my blood pressure is in good control. My primary physician still advises a statin, but in my most recent lipid panel my high-density lipoprotein (HDL) was higher at 103, and my triglycerides far lower at 57 than before I lost weight, so I plan to discuss discontinuing the statin with him at my next visit. I am forever grateful to my obesity medicine physician. I feel as if I have gained years of life.

\section{PHYSICIAN'S PERSPECTIVE}

This patient's story is not unusual. Obesity medicine specialists can frequently achieve similar results provided an aggressive combination of pharmacotherapy, dietary therapy, and behavior intervention is utilized.

Pharmacotherapy combined with energy restriction enhances weight loss $[1,2]$. Phentermine, in use now for over 50 years, is still the most frequently prescribed anti-obesity agent. Originally thought of as an appetite suppressant, we now know that while patients first notice attenuation of hunger, as the drug is continued patients notice that it ameliorates harmful eating behaviors $[3,4]$. The initial appetite suppression may fade with time, but changes in eating behavior persist. As a part of behavioral intervention, obese patients should be taught to have an eating plan and to avoid certain foods. As a substantial weight loss occurs, the physiological changes described as the chronic weight reduced state occur, inducing increased hunger and more frequent thoughts of eating, making adherence to an eating plan more difficult. Without continued pharmacotherapy patients succumb to their physiology, begin to lose control of their eating, and regain weight.

Examples of eating behaviors phentermine may ameliorate in individual patients include eating for comfort, inability to stop eating, inability to stay on an eating plan, eating rapidly, continuous grazing, stress eating, and emotional eating. Phentermine can also mitigate cravings, lessen preoccupation with food, and improve eating control. Some of the more recently approved anti-obesity medicines including bupropion/naltrexone (Contrave) [5] and liraglutide (Saxenda) [6] also have beneficial effects on harmful eating behaviors.

In this case, behavioral intervention focused on eating and exercise behaviors. Phentermine, and later the combination of phentermine and lorcaserin, provided reinforcement for beneficial changes in both types of behaviors.

An important component of the treatment plan in this case was a ketogenic diet, featuring an extremely low carbohydrate intake and an optimal protein intake. The ketogenic diet employed is similar to diets physicians prescribed for patients both with juvenile and adult onset diabetes 100 years ago before the discovery of insulin $[7,8]$. It was already well known at that time that diabetics had extremely low tolerances for carbohydrates of any kind and therefore carbohydrate intake was severely restricted. Since the concentration of ketones in nutritional ketosis, induced with a ketogenic diet, are far lower than the concentration seen 
in diabetic ketoacidosis, ketogenic diets are quite safe for both insulin-dependent and non-insulin-dependent diabetics. Ketogenic diets are now favored by many obesity medicine specialists for treating obese and overweight patients with insulin resistance, with metabolic syndrome, and prediabetes and diabetes.

Piper's experience with her primary care physician is not unusual. Obesity medicine physicians often see overweight and obese patients who are being treated for a wide variety of illnesses, without attention to the excess adiposity that is part of the etiology of these illnesses and contributes to the pathology being treated. This is unfortunate because patients with obesity-associated illnesses invariably experience significant clinical improvement in their other illnesses and have better quality of life with weight loss. Piper is fortunate in that she finally learned on her own that there were physician specialists in obesity medicine and decided to seek help from one.

Salient lessons from this case include the following:

1. Aggressive obesity treatment in overweight and obese prediabetics and diabetics can reverse prediabetes and adult onset diabetes. Chances for reversal of diabetes are highest for patients treated soon after onset [9]. Typically the longer the duration of the diabetes, the lower the reversal rate; however, even if reversal does not occur, nearly all patients will experience improvement in blood sugar control and discontinuation on lower dosages of their diabetes medications. The greater the weight loss, the higher the likelihood of prediabetes or diabetes reversal.

2. Pharmacotherapy with a single or a combination of anti-obesity medicines should be considered for every overweight prediabetic and diabetic patient.

3. Long-term success with diabetes management requires successful maintenance of the weight loss which, for most of these patients, requires long-term pharmacotherapy.

The patient discussed here was initially treated with a ketogenic diet, behavior counseling, and initially phentermine monotherapy and then phentermine combined with lorcaserin. She has now been treated with phentermine and lorcaserin for 5.5 years without cravings and with continued control of eating behavior. Five years after an aggressive medical treatment regimen she continues to maintain a 50-lb weight loss equivalent to a loss of $28 \%$ of her initial weight.

\section{ACKNOWLEDGMENTS}

No funding or sponsorship was received for this study or publication of this article. All named authors meet the International Committee of Medical Journal Editors (ICMJE) criteria for authorship for this manuscript, take responsibility for the integrity of the work as a whole, and have given final approval for the version to be published.

Disclosures. Piper L. Miguelgorry has nothing to disclose with regards to the publication of this article. Ed J. Hendricks has nothing to disclose with regards to the publication of this article.

Compliance with Ethics Guidelines. This article does not contain any new studies with human or animal subjects performed by any of the authors. 
Peer Review. Please note, contrary to the journal's standard double-blind peer review process, as a commentary this article underwent review by a member of the journal's Editorial Board.

Open Access. This article is distributed under the terms of the Creative Commons AttributionNonCommercial 4.0 International License (http://creativecommons.org/licenses/by-nc/4. $0 /$ ), which permits any noncommercial use, distribution, and reproduction in any medium, provided you give appropriate credit to the original author(s) and the source, provide a link to the Creative Commons license, and indicate if changes were made.

\section{REFERENCES}

1. Wadden TA, Berkowitz RI, Sarwer DB, Prus-Wisniewski R, Steinberg C. Benefits of lifestyle modification in the pharmacologic treatment of obesity: a randomized trial. Arch Intern Med. 2001;161:218-27.

2. Haddock CK, Poston WS, Foreyt JP, DiBartolomeo JJ, Warner PO. Effectiveness of Medifast supplements combined with obesity pharmacotherapy: a clinical program evaluation. Eat Weight Disord. 2008;13:95-101.

3. Hendricks EJ, Greenway FL, Westman EC, Gupta AK. Blood pressure and heart rate effects, weight loss and maintenance during long-term phentermine pharmacotherapy for obesity. Obesity (Silver Spring). 2011;19:2351-60.

4. Hendricks EJ. Pharmacotherapy, Chapter 8. In: Steelman GM, Westman EC, editors. Obesity, evaluation and treatment essentials. Boca Raton: CRC; 2016. p. 137-67.

5. Greenway FL, Fujioka K, Plodkowski RA, Mudaliar S, Guttadauria M, Erickson J, et al. Effect of naltrexone plus bupropion on weight loss in overweight and obese adults (COR-I): a multicentre, randomised, double-blind, placebo-controlled, phase 3 trial. Lancet. 2010;376:595-605.

6. Jensterle M, Kocjan T, Kravos NA, Pfeifer M, Janez A. Short-term intervention with liraglutide improved eating behavior in obese women with polycystic ovary syndrome. Endocr Res. 2015;40:133-8.

7. Westman EC, Vernon MC. Has carbohydrate-restriction been forgotten as a treatment for diabetes mellitus? A perspective on the ACCORD study design. Nutr Metab (Lond). 2008;5:10.

8. Osler W, McCrae T. Diabetes mellitus dietary treatment. The principles and practice of medicine. Designed for the use of practitioners and students of medicine. New York: Appleton; 1920. p. 431-4.

9. Steven S, Lim EL, Taylor R. Population response to information on reversibility of type 2 diabetes. Diabet Med. 2013;30(4):e135-8. 